Original article

\title{
Antibiotic use among health science students in an Indian university: A cross sectional study
}

\author{
Samarth Virmani ${ }^{\mathrm{a}}$, Manideep Nandigam ${ }^{\mathrm{a}}$, Bahar Kapoor ${ }^{\mathrm{a}}$, Purva Makhija ${ }^{\mathrm{a}}$, Suma Nair ${ }^{\mathrm{b}, *}$ \\ a Kasturba Medical College, Manipal University, Manipal, Udupi, 576 104, Karnataka, India \\ ${ }^{\mathrm{b}}$ Department of Community Medicine, Kasturba Medical College, Manipal University, Manipal, Udupi, 576 104, Karnataka, India
}

\section{A R T I C L E I N F O}

\section{Article history:}

Received 22 March 2017

Received in revised form 20 April 2017

Accepted 29 April 2017

Available online 6 May 2017

\section{Keywords:}

Antibiotics

Self - prescription

Medical students

Resistance

\begin{abstract}
A B S T R A C T
Background: Antibiotics, one of the frequently prescribed medications in modern medicine is plagued by misuse and consequent development of resistance. We report the knowledge and practice of antibiotic use and the extent of self-medication with antibiotics among health science students of a university in south India.

Methods: A cross-sectional study was carried out that included students from various disciplines such as Medicine, Dentistry, Pharmacy, and Nursing. A random sample of 531 students, were recruited into the study and those students with a history of any chronic disease requiring long-term treatment were excluded.

Results: Almost 58\% reported using antibiotics in the last 3 months and 39\% frequented its use over 3 times in a year. Thirty percent stated that they had procured antibiotics over the counter without a valid prescription. Common ailments that reportedly triggered antibiotic use, ranged from mild fever to skin infections. Medical (25\%) \& Dental (36\%) students declared self-prescription as a frequent practice. $\beta$-lactam group was the most popular group of antibiotics, with over $44 \%$ vouching its use.

Conclusion: There appears to be inadequate adherence to antibiotic policies among the study population warranting periodic training and monitoring. Establishment of an effective antibiotic stewardship could be the way forward.
\end{abstract}

(c) 2017 INDIACLEN. Published by Elsevier, a division of RELX India, Pvt. Ltd. All rights reserved.

\section{Introduction}

Antimicrobial resistance (AMR) is responsible not only for increasing the health care burden on the society but a lot of patients fall victim to avoidable deaths due to infections with resistant strains. The problem has become universal and despite the World Health Organization's best efforts to create awareness regarding this, the challenge continues, given that antibiotics are the most commonly prescribed antimicrobials they are very often misused $^{1,2}$. This indiscriminate use of antibiotics has resulted in bacterial resistance that has considerable clinical and economic impact $^{3,4}$. Evidence shows that even in the developed part of the world almost $60 \%$ of the people are unaware that antibiotics are

\footnotetext{
* Corresponding author.

E-mail addresses: samarthvirmani@gmail.com (S. Virmani), mani107pal@gmail.com (M. Nandigam), baharkapoor@gmail.com (B. Kapoor), purva810@gmail.com (P. Makhija),suma.nair@manipal.edu, sumavimal@gmail.com (S. Nair).
}

ineffective against viruses ${ }^{5}$. On the other hand, in developing countries like India, antibiotics are very often dispensed as an over the counter medication leading to arbitrary use.

Studies have shown self-medication to be a common problem among college students especially in developing countries wherein strict implementation of laws pertaining to dispensing of prescription-only medicines is lacking ${ }^{6,7}$. Partial knowledge and easy access to these medications among this group are likely to perpetrate misuse.

Students in the health sciences sector are the future of the health care of the society and thus, it becomes important to ensure proper awareness regarding antimicrobials, especially antibiotics. In the background of this context, this study was designed with an aim to identify the knowledge and practice of antibiotic use among health science students in a university in South India.

\section{Materials \& methods}

This was a cross sectional study carried out among students of various disciplines (Medicine, Dentistry, Pharmacy, and Nursing) of 
Table 1

Prescription source for obtaining the antibiotics $(\mathrm{N}=456)$.

\begin{tabular}{lllll}
\hline $\begin{array}{l}\text { Source of } \\
\text { Prescription }\end{array}$ & $\begin{array}{l}\text { MBBS } \\
(198)\end{array}$ & $\begin{array}{l}\text { Dental } \\
(89)\end{array}$ & $\begin{array}{l}\text { Nursing } \\
(89)\end{array}$ & $\begin{array}{l}\text { Pharmacy } \\
(80)\end{array}$ \\
& Number (\%) & Number (\%) & Number (\%) & \begin{tabular}{l} 
Number (\%) \\
\hline Doctor
\end{tabular} \\
Pharmacist & $007(71.2)$ & $56(62.9)$ & $87(97.7)$ & $70(87.5)$ \\
Self & $050(25.3)$ & $01(01.1)$ & $02(02.3)$ & $04(05.0)$ \\
\hline
\end{tabular}

a health science University in southern India. Students with history of any chronic disease requiring long- term treatment were excluded from the study as also those who did not give consent.

Estimating the practice of self- medication to be $42 \%$ from literature $^{8}$ for a relative precision of 10 and $95 \%$ level of confidence, the minimum required sample was 531 . Accordingly, these many number of students, proportionate to size from their respective disciplines, were randomly approached by the investigators for recruiting them into the study. Confidentiality was maintained by according the participants a coded identity. Data was analysed using Statistical Package for Social Sciences (SPSS) version 15.0 and presented in proportions.

Ethical clearance was obtained from the Institutional ethics committee (IEC) and due permissions were sought from heads of the respective institutions prior to commencement of the study. Purpose of the study and its objectives, were clearly explained to all the participants, prior to obtaining a written informed consent from them. A pre-designed questionnaire was administered to each participant to collect the necessary information and they were instructed to fill the questionnaire at a place that had sufficient light and was relatively quiet. In the event of more than one participant being present at the same time, discussions among them were discouraged while they attempted the questions and the investigator was present to clarify any doubts regarding the questionnaire.

The questionnaire consisted of 21 questions of which three were open ended. It broadly comprised of two sections. The first section queried regarding general demographical information about the participant. The second section contained questions pertaining to source of antibiotic procurement, pattern and indications of use and awareness regarding antibiotic resistance. Practice regarding antibiotic use was surveyed through closed ended questions such as when the antibiotic was taken, how many times in a year, which antibiotic was commonly used and, whether the full course of antibiotic was adhered to.

\section{Results}

Of the 531 students who were approached, 456 gave consent to participate in the study (response rate of $86 \%$ ). Of those who consented $43.5 \%$ were from medicine (198), $18 \%$ belonged to pharmacy (80), while dental (89) and nursing (89) students constituted $19.5 \%$ each. There were 205 male students (45\%) and 251 female students (55\%).

Almost 48\% reported to having consumed antibiotics in the last 3 months; nearly $60 \%$ at least once a year, while the remaining $40 \%$ claimed its use more than twice a year.

Reported self-medication was high among dental (36\%) and medical students (25\%) while none of the nursing students admitted to it (Table 1$)$. A higher number of dental $(12.4 \%)$ and pharmacy students (13.8\%) stated using the same antibiotic repeatedly irrespective of the illness they suffered from in comparison to medical students $(9.6 \%)$

Relatively more number of dental students (73\%) reported to completing the course of antibiotics, followed by medical students (67.2\%). Nursing students conveyed poor compliance with only one third confirming to completing the course once started (Fig. 1).

As illustrated in Table 2, across disciplines students reported using antibiotics for conditions that could most probably have been viral. A good number (146) of students believed that antibiotics are effective against viral and fungal infections besides bacterial. While majority (77.6\%) of the students acquired antibiotics with a valid prescription from a physician, there were others, who obtained it from various unauthorised sources such as over-the-counter with self- prescription, free samples and leftover antibiotics from friends.

Approximately $11 \%$ (50) students were unaware about the name of the antibiotic that they used. This information was included in the 'Others' category in Fig. 2.

\section{Discussion}

The objective of this study was to assess the practice and knowledge regarding antibiotic use among Indian students

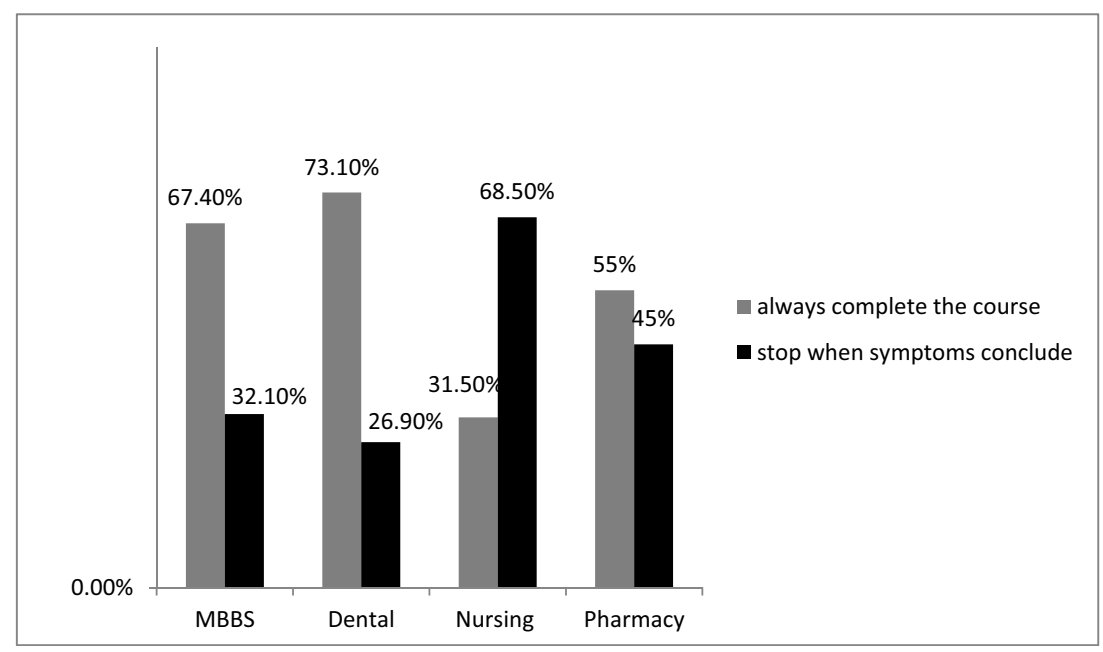

Fig. 1. Pattern of antibiotic intake once started $(n=456)$. 
Table 2

Common conditions for which antibiotics were used $n=456$.

\begin{tabular}{|c|c|c|c|c|c|c|}
\hline $\begin{array}{l}\text { Study } \\
\text { Participants }\end{array}$ & $\begin{array}{l}\text { Middle ear Infection } \\
\text { Number } \\
(\%)\end{array}$ & $\begin{array}{l}\text { Clear Nasal Discharge } \\
\text { Number } \\
(\%)\end{array}$ & $\begin{array}{l}\text { Purulent Nasal Discharge } \\
\text { Number } \\
(\%)\end{array}$ & $\begin{array}{l}\text { Sore Throat } \\
\text { Number } \\
(\%)\end{array}$ & $\begin{array}{l}\text { Flu Like symptoms } \\
\text { Number } \\
\mathrm{r}(\%)\end{array}$ & $\begin{array}{l}\text { Skin Infections } \\
\text { Number } \\
\text { (\%) }\end{array}$ \\
\hline Medical & $186(94.0)$ & $59(28.0)$ & $181(91.4)$ & $158(79.8)$ & $86(43.4)$ & $173(87.4)$ \\
\hline Dental & 068 (69.4) & $45(50.6)$ & $071(79.8)$ & $076(85.4)$ & $63(70.8)$ & $075(84.3)$ \\
\hline Pharmacy & 067 (75.3) & 35 (39.3) & 056 (62.9) & $063(70.8)$ & $73(82.0)$ & 081 (91.0) \\
\hline Nursing & 059 (73.7) & $33(41.2)$ & $052(65.0)$ & $042(52.5)$ & $54(67.5)$ & 067 (83.7) \\
\hline
\end{tabular}

belonging to the health sector. Accordingly, more than $40 \%$ of students admitted to using antibiotics more than twice a year.

About 26\% of medical students admitted to self-medication and this was much lower than that found among medical students in a Southern Iranian university and a University in Northern Nigeria, which was approximately $42 \%$ and $38 \%$ respectively ${ }^{8,9}$. The findings were however, comparable to that of the medical students in a university at Jordon $(29 \%)^{10}$. Almost $36 \%$ of dental students proclaimed self-medication with antibiotics, which is comparatively lesser than the findings from that of the Nigerian dental students $(52 \%)^{11}$.

Medical and nursing students were less likely to use the same antibiotics irrespective of the illness in comparison to dental and pharmacy students. This could be due to a greater stress on types of infections and antibiotic use in their curriculum.

In our study, $68.5 \%$ of the nursing students reportedly did not complete their course of antibiotics. This was considerably alarming as failure to complete an antibiotic course is a breeding ground for resistant bacteria to emerge. Pharmacy students were a close second, with $45 \%$ students not completing the course of antibiotics. Nearly $33 \%$ of the medical students were also not likely to finish the antibiotic course once started. These findings are much lower than that observed among the medical students in Northern Nigeria (51\%) and Southern Iranian University $(67.5 \%)^{8,9}$. A study conducted in Jordan reported $80 \%$ non- compliance among non-medical students while $50 \%$ of medical students were also guilty of the same ${ }^{10}$.

In concordance with the findings from the studies conducted in Nigeria ${ }^{9,11,13}, \operatorname{Iran}^{8}, \mathrm{UAE}^{12}$ and India ${ }^{14}, \beta$-lactams were the most commonly abused group of antibiotics. However, our study could not, further sub-categorize the most frequently used $\beta$-lactam antibiotic and this can be grounds for further study as it will give us more specific information about particular antibiotics, which are irrationally used, thereby increasing their susceptibility to develop resistance.

Knowledge regarding sensitivity of microorganisms against antibiotics was grossly lacking among more than 30\% of the students who believed that antibiotics are used in the treatment of infections with viruses or fungi or both.

A significant number of students across disciplines in our study believed that antibiotics are effective against the common cold and flu. This was much higher than that observed among health science students of a Ugandan university, where about $20 \%$ erred on the side of believing that the common cold required treatment with antibiotics ${ }^{15}$. This indicates a need for undertaking education programmes highlighting the role of antibiotics in specific infections. This may help in minimizing irrational use of antibiotics.

There are inherent limitations of the study. Based as it is, on self - reported cross-sectional study findings, we cannot rule out the possibility of bias resulting in an underestimation of the actual use and compliance. Further, while the study identified a difference in behaviour towards antibiotic use among the various student groups, it did not effectively capture the factors that determine this difference. A longitudinal design could help us establish these findings with more certainty.

\section{Conclusion}

The study findings show the existence of inadequate sensitivity to rational antibiotic use and low compliance with standard guidelines among the students in a health science university

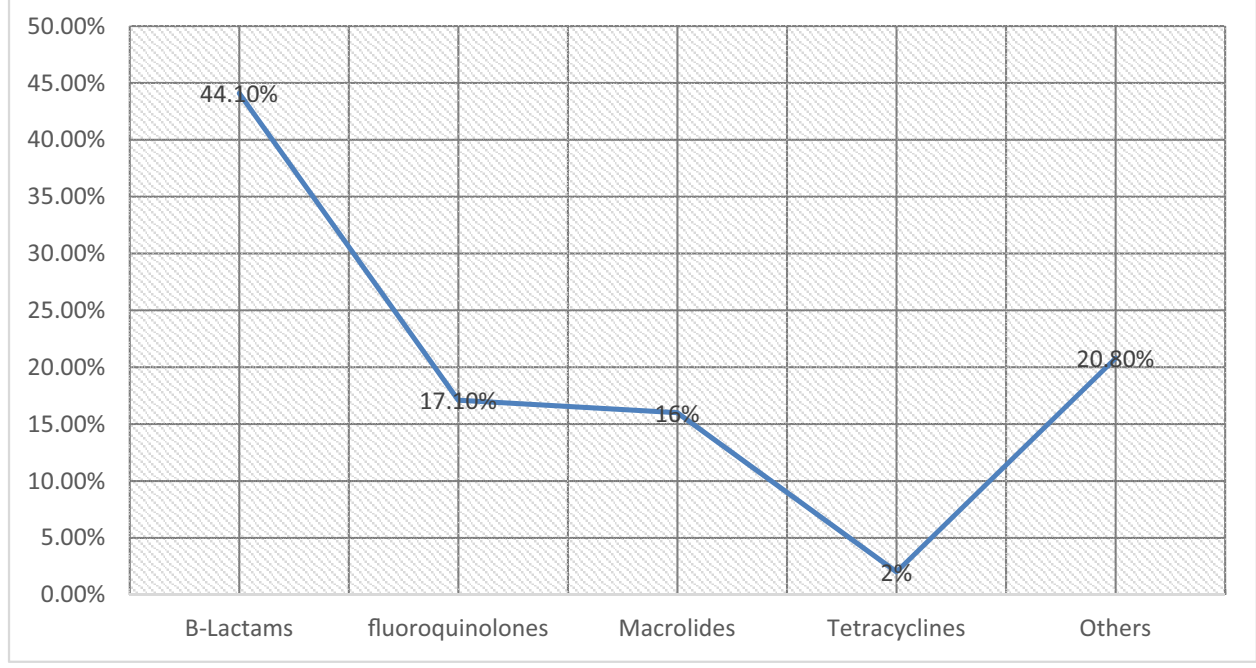

Fig. 2. Commonly used antibiotics $(N=456)$. 
setting. There is an urgent requirement to address these issues. Periodic training in the form of workshops and symposiums dedicated to the theme of safe antibiotic practice could create the necessary awareness and reinforce the need to comply with standard guidelines. Additionally, the establishment of a stringent antibiotic policy within the university healthcare institutions and hospitals could help budding healthcare professionals emulate ethical use of these drugs.

\section{Conflict of interest}

None.

\section{External funding}

None.

\section{Acknowledgements:}

The authors are grateful to the students who voluntarily took part in the study. We wish to acknowledge the internal support provided by the Department of Community Medicine, Kasturba Medical College, Manipal and Manipal University.

\section{References}

1. World Health Organization's Report on Antibiotic resistance [Internet]. Antibiotic resistance-Fact Sheet-October 2016. Available from: http://www. who.int/mediacentre/factsheets/antibiotic-resistance/en/.

2. Centers for Disease Control and Prevention (CDC) features [Internet]. Antibiotics aren't always the answer. [Accessed on 2015 April 30]. Available from: http://www.cdc.gov/Features/GetSmart.
3. Giske CG, Monnet DL, Cars O, Carmeli Y. Clinical and economic impact of common multidrug-resistant gram-negative bacilli. Antimicrob Agents Chemother. 2008;52:813-821.

4. Nathwani D, Raman G, Sulham K, Gavaghan M, Menon V. Clinical and economic consequences of hospital-acquired resistant and multidrugresistant Pseudomonas aeruginosa infections: a systematic review and metaanalysis. Antimicrob Resist Infect Control. 2014;3:3210.1186/2047-2994-3-32.

5. Maragakis LL, Perencevich EN, Cosgrove SE. Clinical and economic burden of antimicrobial resistance. Exp Rev Anti Infect Ther. 2008;6:751-763.

6. Harbarth S, Samore MH. Antimicrobial resistance determinants and future control. Emerg Infect Dis. 2005;11:794-801.

7. Sawalh AF. A descriptive study of self-medication practices among Palestinian medical and nonmedical University students. Res Soc Adm Pharm. 2008;4:164172.

8. Sarahroodi S, Arzi A, Sawalha AF, Ashtarinezhad A. Antibiotics self-medication among Southern Iranian University students. Int J Pharmacol. 2010;6(1):48-52.

9. Fadare JO, Tamuno I. Antibiotic self-medication among university medical undergraduates in Northern Nigeria. J Public Health Epidemiol. 2011;3(5):217220.

10. Suaifan Ghadeer ARY, Shehadeh Suaifan Mayadah, Darwish Dana A, Al-Ije Hebah, Yousef Al-Motassem M, Darwish Rula M. A cross-sectional study on knowledge, attitude and behavior related to antibiotic use and resistance among medical and non-medical university students in Jordan. Afr J Pharm Pharmacol. 2012;6(10):763-770.

11. Ehigiator O, Azodo CC, Ehikhamenor EE. Self-medication with antibiotics among Nigerian dental students. Tanz Dent J. 2010;16(2):48-54.

12. Abasaeed Abobakr, Vlcek Jiri, Abuelkhair Mohammed. Ales Kubena Selfmedication with antibiotics by the community of Abu Dhabi Emirate, United Arab Emirates. J Infect Dev Ctries. 2009;3(7):491-497.

13. Olayemi OJ, Olayinka BO, Musa AI. Evaluation of antibiotic self-medication pattern amongst undergraduate students of Ahmadu Bello University (Main Campus), Zaria. Res J App Sci Eng Technol. 2010;2(1):35-38.

14. Bala R, Singh H, Kaur KPG, Kohli K. Knowledge and attitude towards antimicrobial self-medication usage: a cross sectional study among medical and nursing students. Int J Basic Clin Pharmacol. 2013;2(4):428-432.

15. Jacqueline Nambatya, Sarah Nyairo, Micheal Bironse, Samantha Kachwiya, Norman Musigunzi, Adriane Kamulegeya. Antibiotic use knowledge and behaviour at a Ugandan University. Int J Infect Control. 2011;7(4):1-7. 